\title{
Rectal follicular lymphoma
}

\author{
F. Castro-Poças ${ }^{1,2}$ - T. Araújo ${ }^{3}$ - A. Duarte ${ }^{4}$ C. Lopes $^{2,5}$ • M. Mascarenhas-Saraiva ${ }^{1,2}$
}

Accepted: 8 March 2015 / Published online: 19 March 2015

(C) Springer-Verlag Berlin Heidelberg 2015

Dear Editor:

Colonoscopy was performed to a 65 -year-old female with tenesmus that showed, in the distal rectum, a bulging lesion of $3 \mathrm{~cm}$ covered with normal appearance mucosa.

We performed an endoscopic ultrasonography (EUS) that showed a polypoid morphology lesion, heterogeneous, mainly hypoechoic, located in the deep mucosa and submucosa layers; the lesion was well delimited with regular borders and occupied one third of the rectum circumference. There was no sure diagnosis, being most likely a fibrolipoma, a granular cell tumor, a neuroendocrine tumor, or a fibrovascular polyp. It was proposed to the patient to perform a transanal resection or an EUS with fine needle aspiration. She accepted the transanal resection.

She had history of a nodal non-Hodgkin lymphoma treated 3 years before with rituximab, cyclophosphamide, vincristine, and prednisolone and a surgical treatment of urogenital prolapse 1 year before using a plastic prosthesis.

The histopathologic examination revealed a rectal follicular lymphoma, grade one. The staging procedures showed no other site of disease.

F. Castro-Poças

castro.pocas@sapo.pt

1 Department of Gastroenterology, Institute of CUF-ManoPH, Rua Fonte das Sete Bicas 170, 4460-188 Senhora da Hora, Matosinhos, Porto, Portugal

2 Institute of Biomedical Sciences Abel Salazar, University of Porto, Porto, Portugal

3 Department of Gastroenterology, Santo António Hospital, Porto Hospital Center, Porto, Portugal

4 Department of Surgery, São João Hospital Center, Porto, Portugal

5 Department of Pathology, Institute of CUF-ManoPH, Porto, Portugal

\section{Discussion}

Although the gastrointestinal tract is one of the most common extranodal sites, the frequency of colon and rectum lymphoma, primary or involved by systemic disease, is rare [1]. It was not considered as a hypothesis due to its rarity and the fact that the patient had been disease-free during several years. It usually presents endoscopically as fungating, ulcerative, infiltrative, ulcerofungating, and ulceroinfiltrative types, being fungating and ulcerofungating the most frequent [2]. There are few cases reporting appearance as a submucosal lesion, and to our best knowledge, none of them was a follicular lymphoma [3]. A lymphoma involving the colon and rectum is rare and can occur either as a primary colorectal lymphoma or as a manifestation of systemic disease.

A high suspicious level of extranodal lymphoma site is necessary for detecting neoplastic lesions. The rectal lesion was not characteristic of a rectal lymphoma; thus, the surgery resection was vital.

Disclosures The authors have no financial disclosures or conflicts of interest to declare.

\section{References}

1. Zucca E, Roggero E, Bertoni F, Cavalli F (1997) Primary extranodal non-Hodgkin's lymphomas. Part 1: gastrointestinal, cutaneous and genitourinary lymphomas. Ann Oncol 8:727737

2. Myung S, Joo K, Yang S et al (2003) Clinicopathologic features of ileocolonic malignant lymphoma: analysis according to colonoscopic classification. Gastrointest Endosc 57:343-347

3. Jung I, Kim S, Kim K et al (2012) A case of primary ovarian lymphoma presenting as a rectal submucosal tumor. J Korean Soc Coloproctol 28:111-115 